\title{
Sharper ABC-based bounds for congruent polynomials
}

\author{
par DANIEL J. BERNSTEIN
}

\begin{abstract}
RÉSumÉ. Agrawal, Kayal, et Saxena ont récemment introduit une nouvelle méthode pour montrer qu'un entier est premier. La vitesse de cette méthode dépend des minorations prouvées pour la taille du semi-groupe multiplicatif engendré par plusieurs polynômes modulo un autre polynôme $h$. Voloch a trouvé une application du théoreme $\mathrm{ABC}$ de Stothers et Mason dans ce contexte: sous de petites hypothèses, des polynômes distincts $A, B, C$ de degré au plus $1.2 \operatorname{deg} h-0.2 \operatorname{deg} \operatorname{rad} A B C$ ne peuvent pas être tous congrus modulo $h$. Nous présentons deux améliorations de la partie combinatoire de l'argument de Voloch. La première amélioration augmente $1.2 \operatorname{deg} h-0.2 \operatorname{deg} \operatorname{rad} A B C$ en $2 \operatorname{deg} h-$ $\operatorname{deg} \operatorname{rad} A B C$. La deuxième amélioration est une généralisation à $A_{1}, \ldots, A_{m}$ de degré au plus $((3 m-5) /(3 m-7)) \operatorname{deg} h-(6 /(3 m-$ 7) $m$ ) deg $\operatorname{rad} A_{1} \cdots A_{m}$, avec $m \geq 3$.
\end{abstract}

AbStract. Agrawal, Kayal, and Saxena recently introduced a new method of proving that an integer is prime. The speed of the Agrawal-Kayal-Saxena method depends on proven lower bounds for the size of the multiplicative semigroup generated by several polynomials modulo another polynomial $h$. Voloch pointed out an application of the Stothers-Mason ABC theorem in this context: under mild assumptions, distinct polynomials $A, B, C$ of degree at most $1.2 \operatorname{deg} h-0.2 \operatorname{deg} \operatorname{rad} A B C$ cannot all be congruent modulo $h$. This paper presents two improvements in the combinatorial part of Voloch's argument. The first improvement moves the degree bound up to $2 \operatorname{deg} h-\operatorname{deg} \operatorname{rad} A B C$. The second improvement generalizes to $m \geq 3$ polynomials $A_{1}, \ldots, A_{m}$ of degree at most $((3 m-5) /(3 m-7)) \operatorname{deg} h-(6 /(3 m-7) m) \operatorname{deg} \operatorname{rad} A_{1} \cdots A_{m}$.

Manuscrit reçu le 3 octobre 2003.

The author was supported by the National Science Foundation under grant DMS-0140542, and by the Alfred P. Sloan Foundation. He used the libraries at the Mathematical Sciences Research Institute and the University of California at Berkeley. Permanent ID of this document: 1d9e079cee20138de8e119a99044baa3. 


\section{Introduction}

Fix a nonconstant univariate polynomial $h$ over a field $k$. Assume that the characteristic of $k$ is at least $3 \operatorname{deg} h-1$. The main theorem of this paper, Theorem 2.3 , states that if $m \geq 3$ distinct polynomials $A_{1}, \ldots, A_{m}$ are all congruent modulo $h$ and coprime to $h$ then

$\max \left\{\operatorname{deg} A_{1}, \ldots, \operatorname{deg} A_{m}\right\}>\frac{3 m-5}{3 m-7} \operatorname{deg} h-\frac{6}{(3 m-7) m} \operatorname{deg} \operatorname{rad} A_{1} \cdots A_{m}$.

As usual, $\operatorname{rad} X$ means the largest monic squarefree divisor of $X$, i.e., the product of the monic irreducibles dividing $X$. If $\operatorname{deg} \operatorname{rad} A_{1} \cdots A_{m}<$ $(m / 3) \operatorname{deg} h$ then the bound in Theorem 2.3 is better than the obvious bound $\max \left\{\operatorname{deg} A_{1}, \ldots, \operatorname{deg} A_{m}\right\}>\operatorname{deg} h-1$.

For example, if distinct polynomials $A, B, C$ are congruent modulo $h$ and coprime to $h$ then $\max \{\operatorname{deg} A, \operatorname{deg} B, \operatorname{deg} C\}>2 \operatorname{deg} h-\operatorname{deg} \operatorname{rad} A B C$. No better bound is possible in this level of generality: if $h=x^{10}-1$, $A=x^{20}, B=x^{10}$, and $C=1$ then $\operatorname{rad} A B C=\operatorname{rad} x^{30}=x$ so $2 \operatorname{deg} h-$ $\operatorname{deg} \operatorname{rad} A B C=19$.

The proof relies on the Stothers-Mason ABC theorem. Analogous bounds in the number-field case follow from the $\mathrm{ABC}$ conjecture.

Previous work. Voloch in [3] proved that $\max \{\operatorname{deg} A, \operatorname{deg} B, \operatorname{deg} C\}>$ $1.2 \mathrm{deg} h-0.2 \mathrm{deg} \operatorname{rad} A B C$. This paper improves Voloch's result in two ways:

- This paper is quantitatively stronger, in the interesting case that $\operatorname{deg} \operatorname{rad} A B C<\operatorname{deg} h$.

- This paper applies to larger values of $m$.

Application. Inside the unit group $(k[x] / h)^{*}$ consider the subgroup $G$ generated by $\{x-s: s \in S\}$, where $S \subseteq k$ and $0 \notin h(S)$. The AgrawalKayal-Saxena primality-proving method requires a lower bound on \#G for groups $G$ of this type, typically with $\# S=\operatorname{deg} h$. The primality-proving method becomes faster as the lower bound on \#G increases, as discussed in $[1$, Section 7].

This paper shows that

$$
\# G \geq \frac{1}{m-1}\left(\begin{array}{c}
\lfloor((3 m-5) /(3 m-7)) \operatorname{deg} h-(6 /(3 m-7) m) \# S\rfloor+\# S \\
\# S
\end{array}\right)
$$

for any $m \geq 3$. Indeed, the binomial coefficient is the number of products of powers of $\{x-s\}$ in $k[x]$ of degree at most

$$
\lfloor((3 m-5) /(3 m-7)) \operatorname{deg} h-(6 /(3 m-7) m) \# S\rfloor ;
$$

$m$ distinct such products cannot all have the same image modulo $h$. 
In particular, if $\# S=\operatorname{deg} h$, then $\# G \geq \frac{1}{3}\left(\begin{array}{c}\lfloor .1 \operatorname{deg} h\rfloor \\ \operatorname{deg} h\end{array}\right) \approx 4.27689^{\operatorname{deg} h}$. Compare this to the bound $\# G \geq\left(\begin{array}{c}2 \operatorname{deg} h-1 \\ \operatorname{deg} h\end{array}\right) \approx 4^{\operatorname{deg} h}$ obtained from a degree bound of $\operatorname{deg} h-1$. Note that the improvement requires $m>3$.

Different methods from [3] produce a lower bound around $5.828^{\operatorname{deg} h}$, so the ABC-based techniques in [3] and in this paper have not yet had an impact on the speed of primality proving. However, I suspect that these techniques have not yet reached their limits.

\section{Proofs}

Theorem 2.1. Let $k$ be a field. Let $h$ be a positive-degree element of the polynomial ring $k[x]$. Assume that $1,2,3, \ldots, 3 \operatorname{deg} h-2$ are invertible in k. Let $A, B, C$ be distinct nonzero elements of $k[x]$. If $\operatorname{gcd}\{A, B, C\}=$ 1 and $A \equiv B \equiv C(\bmod h)$ then $\max \{\operatorname{deg} A, \operatorname{deg} B, \operatorname{deg} C\}>2 \operatorname{deg} h-$ $\operatorname{deg} \operatorname{rad} A B C$.

Proof. Permute $A, B, C$ so that $\operatorname{deg} A=\max \{\operatorname{deg} A, \operatorname{deg} B, \operatorname{deg} C\}$.

The nonzero polynomial $A-B$ is a multiple of $h$, so $\operatorname{deg} A \geq \operatorname{deg}(A-B) \geq$ $\operatorname{deg} h>0$; thus deg $\operatorname{rad} A B C>0$.

If $\operatorname{deg} A \geq 2 \operatorname{deg} h$ then $\operatorname{deg} A>2 \operatorname{deg} h-\operatorname{deg} \operatorname{rad} A B C$; done.

Define $U=(B-C) / h, V=(C-A) / h$, and $W=(A-B) / h$. Then $U \neq 0 ; V \neq 0 ; W \neq 0 ; U, V, W$ each have degree at most $\operatorname{deg} A-\operatorname{deg} h$; and $U A+V B+W C=0$. Define $D=\operatorname{gcd}\{U A, V B, W C\}$.

If $\operatorname{deg} D=\operatorname{deg} U A$ then $U A$ divides $V B, W C$; so $A$ divides $V W A, V W B$, $V W C$; so $A$ divides $\operatorname{gcd}\{V W A, V W B, V W C\}=V W$; but $V W \neq 0$, so $\operatorname{deg} A \leq \operatorname{deg} V W \leq 2(\operatorname{deg} A-\operatorname{deg} h) ; \operatorname{so} \operatorname{deg} A \geq 2 \operatorname{deg} h$; done.

Assume from now on that $\operatorname{deg} D<\operatorname{deg} U A$ and that $\operatorname{deg} A \leq 2 \operatorname{deg} h-1$. Then $\operatorname{deg}(U A / D)$ is between 1 and $2 \operatorname{deg} A-\operatorname{deg} h \leq 3 \operatorname{deg} h-2$; so the derivative of $U A / D$ is nonzero. Also $U A / D+V B / D+W C / D=0$, and $\operatorname{gcd}\{U A / D, V B / D, W C / D\}=1$. By Theorem 3.1 below, $\operatorname{deg}(U A / D)<$ $\operatorname{deg} \operatorname{rad}((U A / D)(V B / D)(W C / D))=\operatorname{deg} \operatorname{rad}\left(U V W A B C / D^{3}\right)$.

The proof follows Voloch up to this point. Voloch next observes that $D$ divides $\operatorname{gcd}\{U V W A, U V W B, U V W C\}=U V W \operatorname{gcd}\{A, B, C\}=U V W$. I claim that more is true: $D \operatorname{rad}\left(U V W A B C / D^{3}\right)$ divides $U V W \operatorname{rad} A B C$.

(In other words: If $d=\min \{u+a, v+b, w+c\}$ and $\min \{a, b, c\}=0$ then $d+[u+v+w+a+b+c>3 d] \leq u+v+w+[a+b+c>0]$. Proof: Without loss of generality assume $a=0$. Then $d \leq u \leq u+v+w$. If $d<u+v+w$ then $d+[\cdots] \leq d+1 \leq u+v+w \leq u+v+w+[\cdots]$ as claimed. If $a+b+c>0$ then $d+[\cdots] \leq u+v+w+1=u+v+w+[\cdots]$ as claimed. Otherwise $u+v+w+a+b+c=d \leq 3 d$ so $d+[u+v+w+a+b+c>$ $3 d]=d \leq u+\dot{v}+w \leq u+v+w+[\cdots]$ as claimed.)

Thus $\operatorname{deg} U A<\operatorname{deg}\left(D \operatorname{rad}\left(U V W A B C / D^{3}\right)\right) \leq \operatorname{deg}(U V W \operatorname{rad} A B C)$. Hence $\operatorname{deg} A<\operatorname{deg}(V W \operatorname{rad} A B C) \leq 2(\operatorname{deg} A-\operatorname{deg} h)+\operatorname{deg} \operatorname{rad} A B C$; i.e., $\operatorname{deg} A>2 \operatorname{deg} h-\operatorname{deg} \operatorname{rad} A B C$ as claimed. 
Theorem 2.2. Let $k$ be a field. Let $h$ be a positive-degree element of the polynomial ring $k[x]$. Assume that $1,2,3, \ldots, 3 \operatorname{deg} h-2$ are invertible in $k$. Let $A, B, C$ be distinct nonzero elements of $k[x]$. If $\operatorname{gcd}\{A, B, C\}$ is coprime to $h$ and $A \equiv B \equiv C(\bmod h)$ then

$\max \{\operatorname{deg} A, \operatorname{deg} B, \operatorname{deg} C\}$

$>2 \operatorname{deg} h-\operatorname{deg} \operatorname{rad} A-\operatorname{deg} \operatorname{rad} B-\operatorname{deg} \operatorname{rad} C$

+ deg $\operatorname{rad} \operatorname{gcd}\{A, B\}+\operatorname{deg} \operatorname{rad} \operatorname{gcd}\{A, C\}+\operatorname{deg} \operatorname{rad} \operatorname{gcd}\{B, C\}$.

Proof. Write $G=\operatorname{gcd}\{A, B, C\}$. Then $G$ is coprime to $h$, so $A / G \equiv B / G \equiv$ $C / G(\bmod h)$. By Theorem 2.1,

$$
\begin{aligned}
\max \left\{\operatorname{deg} \frac{A}{G}, \operatorname{deg} \frac{B}{G}, \operatorname{deg} \frac{C}{G}\right\} & >2 \operatorname{deg} h-\operatorname{deg} \operatorname{rad} \frac{A B C}{G G G} \\
& \geq 2 \operatorname{deg} h-\operatorname{deg} \operatorname{rad} A B C .
\end{aligned}
$$

Furthermore, $\operatorname{deg} G \geq \operatorname{deg} \operatorname{rad} G=\operatorname{deg} \operatorname{rad} A B C-\operatorname{deg} \operatorname{rad} A-\operatorname{deg} \operatorname{rad} B-$ $\operatorname{deg} \operatorname{rad} C+\operatorname{deg} \operatorname{rad} \operatorname{gcd}\{A, B\}+\operatorname{deg} \operatorname{rad} \operatorname{gcd}\{A, C\}+\operatorname{deg} \operatorname{rad} \operatorname{gcd}\{B, C\}$ by inclusion-exclusion. Add.

Theorem 2.3. Let $k$ be a field. Let $h$ be a positive-degree element of the polynomial ring $k[x]$. Assume that $1,2,3, \ldots, 3 \operatorname{deg} h-2$ are invertible in $k$. Let $S$ be a finite subset of $k[x]-\{0\}$, with $\# S \geq 3$. If each element of $S$ is coprime to $h$, and all the elements of $S$ are congruent modulo $h$, then

$$
\max \{\operatorname{deg} A: A \in S\}>\frac{3 \# S-5}{3 \# S-7} \operatorname{deg} h-\frac{6}{(3 \# S-7) \# S} \operatorname{deg} \operatorname{rad} \prod_{A \in S} A .
$$

For example, $\max \{\operatorname{deg} A: A \in S\}>1.4 \operatorname{deg} h-0.3 \operatorname{deg} \operatorname{rad} \prod_{A \in S} A$ if $\# S=4$, and $\max \{\operatorname{deg} A: A \in S\}>1.25 \operatorname{deg} h-0.15 \operatorname{deg} \operatorname{rad} \prod_{A \in S} A$ if $\# S=5$.

Proof. Define $d=\max \{\operatorname{deg} A: A \in S\}$ and $e=\operatorname{deg} \operatorname{rad} \prod_{A \in S} A$. Then

$d>2 \operatorname{deg} h-\operatorname{deg} \operatorname{rad} A-\operatorname{deg} \operatorname{rad} B-\operatorname{deg} \operatorname{rad} C$

$$
+\operatorname{deg} \operatorname{rad} \operatorname{gcd}\{A, B\}+\operatorname{deg} \operatorname{rad} \operatorname{gcd}\{A, C\}+\operatorname{deg} \operatorname{rad} \operatorname{gcd}\{B, C\}
$$

for any distinct $A, B, C \in S$ by Theorem 2.2. Average this inequality over all choices of $A, B, C$ to see that $d>2 \operatorname{deg} h-3 \operatorname{avg}_{A} \operatorname{deg} \operatorname{rad} A+$ $3 \operatorname{avg}_{A \neq B} \operatorname{deg} \operatorname{rad} \operatorname{gcd}\{A, B\}$. On the other hand, $e \geq \# S \operatorname{avg}_{A} \operatorname{deg} \operatorname{rad} A-$ $\left(\begin{array}{c}\# S \\ 2\end{array}\right) \operatorname{avg}_{A \neq B} \operatorname{deg} \operatorname{rad} \operatorname{gcd}\{A, B\}$ by inclusion-exclusion, so

$$
d+\frac{3}{\# S} e>2 \operatorname{deg} h-\frac{3 \# S-9}{2} \operatorname{avg}_{A \neq B} \operatorname{deg} \operatorname{rad} \operatorname{gcd}\{A, B\} .
$$

Note that $3 \# S-9 \geq 0$ since $\# S \geq 3$.

One can bound each term $\operatorname{deg} \operatorname{rad} \operatorname{gcd}\{A, B\}$ by the simple observation that $A / \operatorname{gcd}\{A, B\}$ and $B / \operatorname{gcd}\{A, B\}$ are distinct congruent polynomials 
of degree at most $d-\operatorname{deg} \operatorname{gcd}\{A, B\} ;$ thus $d-\operatorname{deg} \operatorname{gcd}\{A, B\} \geq \operatorname{deg} h$, so $\operatorname{deg} \operatorname{rad} \operatorname{gcd}\{A, B\} \leq d-\operatorname{deg} h$. Hence

$$
\begin{array}{r}
d+\frac{3}{\# S} e>2 \operatorname{deg} h-\frac{3 \# S-9}{2}(d-\operatorname{deg} h) ; \\
\text { i.e., } d>((3 \# S-5) /(3 \# S-7)) \operatorname{deg} h-(6 /(3 \# S-7) \# S) e .
\end{array}
$$

\section{Appendix: the ABC theorem}

Theorem 3.1 is a typical statement of the Stothers-Mason ABC theorem, included in this paper for completeness. The proof given here is due to Noah Snyder; see [2].

Theorem 3.1. Let $k$ be a field. Let $A, B, C$ be nonzero elements of the polynomial ring $k[x]$ with $A+B+C=0$ and $\operatorname{gcd}\{A, B, C\}=1$. If $\operatorname{deg} A \geq$ $\operatorname{deg} \operatorname{rad} A B C$ then $A^{\prime}=0$.

In fact, $A^{\prime}=B^{\prime}=C^{\prime}=0$. As usual, $X^{\prime}$ means the derivative of $X$; the relevance of derivatives is that $X / \operatorname{rad} X$ divides $X^{\prime}$.

Proof. Note that $\operatorname{gcd}\{A, B\}=\operatorname{gcd}\{A, B,-(A+B)\}=\operatorname{gcd}\{A, B, C\}=1$. By the same argument, $\operatorname{gcd}\{A, C\}=1$ and $\operatorname{gcd}\{B, C\}=1$.

$C / \operatorname{rad} C$ divides both $C$ and $C^{\prime}$, so it divides $C^{\prime} B-C B^{\prime}$. Similarly, $B / \mathrm{rad} B$ divides $C^{\prime} B-C B^{\prime}$. Furthermore, $C^{\prime}=-\left(A^{\prime}+B^{\prime}\right)$, so $C^{\prime} B-C B^{\prime}=$ $-\left(A^{\prime}+B^{\prime}\right) B+(A+B) B^{\prime}=A B^{\prime}-A^{\prime} B$; thus $A / \operatorname{rad} A$ divides $C^{\prime} B-C B^{\prime}$.

The ratios $A / \operatorname{rad} A, B / \operatorname{rad} B, C / \operatorname{rad} C$ are pairwise coprime, so their product $A B C / \mathrm{rad} A B C$ divides $C^{\prime} B-C B^{\prime}$. But by hypothesis

$$
\operatorname{deg} \frac{A B C}{\operatorname{rad} A B C}=\operatorname{deg} A B C-\operatorname{deg} \operatorname{rad} A B C \geq \operatorname{deg} B C>\operatorname{deg}\left(C^{\prime} B-C B^{\prime}\right) ;
$$

so $C^{\prime} B-C B^{\prime}=0$; so $A B^{\prime}-A^{\prime} B=0$; so $A$ divides $A^{\prime} B$; but $A$ and $B$ are coprime, so $A$ divides $A^{\prime} ;$ but $\operatorname{deg} A>\operatorname{deg} A^{\prime}$, so $A^{\prime}=0$.

\section{References}

[1] Daniel J. Bernstein. Proving primality in essentially quartic random time, to appear, Mathematics of Computation. Available from http://cr.yp.to/papers.html\#quartic.

[2] NOAH SNYDER. An alternate proof of Mason's theorem, Elemente der Mathematik 55 (2000), 93-94. ISSN 0013-6018. MR 2001g:11033. Available from http://www.springerlink. com/openurl . asp?genre $=$ article\&issn $=0013-6018 \&$ volume $=55 \&$ issue $=3 \&$ spage $=93$.

[3] JosÉ FeliPE VOLOCH, On some subgroups of the multiplicative group of finite rings, Journal de Théorie des Nombres de Bordeaux 16 (2004), 233-238. ISSN 1246-7405. Available from http://www .ma.utexas. edu/users/voloch/preprint.html.

Daniel J. BERNSTEIN

Department of Mathematics, Statistics, and Computer Science (M/C 249)

The University of Illinois at Chicago

Chicago, IL 60607-7045

E-mail : djb@cr.yp.to 